\title{
InGaP/GaAs/Ge MULTI-JUNCTION SOLAR CELL EFFICIENCY IMPROVEMENTS USING EPITAXIAL GERMANIUM
}

\author{
Daniel J. Aiken \\ Sandia National Laboratories, Albuquerque, NM 87185
}

\begin{abstract}
Triple junction InGaP/GaAs/Ge solar cells are highly current mismatched due to the excess current generating capability of the germanium subcell. This severe current mismatch invites new approaches for increasing performance beyond that of current triple junctions: Presented here are two approaches for improving the efficiency of III- $V$ multi-junctions beyond that of current triple junction technology. Both of these approaches involve the use of thin epitaxial germanium and do not require the development of new $\sim 1 \mathrm{eV}$ photovoltaic materials. The theoretical AMO efficiency is over $30 \%$. Modeling suggests the potential for over $1.5 \%$ absolute efficiency gain with respect to current InGaP/GaAs/Ge triple junction solar cells.
\end{abstract}

\section{INTRODUCTION}

The state-of-the-art solar cell for high efficiency, high value applications such as space power is the triple junction solar cell based on the monolithic series interconnection of InGaP, GaAs, and $\mathrm{Ge}$ subcells. Germanium is suitable as a substrate material for these devices due to near lattice match with $\mathrm{GaAs}$ and favorable mechanical properties. However, the $0.66 \mathrm{eV}$ bandgap of $\mathrm{Ge}$ is far from the $-1.1 \mathrm{eV}$ that is ideal when series connected with InGaP and GaAs under the AMO spectrum. The result is an extreme current mismatch and large amount of unusable sunlight absorbed by the $\mathrm{Ge}$ subcell. Table 1 compares the maximum achievable short circuit current (Jsc) of the three subcells in a triple junction for the limiting case of infinite subcell thickness.

Table 1. Maximum achievable Jsc for each subcell in an InGaP/GaAs/Ge triple junction.

\begin{tabular}{|c|c|}
\hline Subcell & Maximum achievable Jsc $\left(\mathrm{mA} / \mathrm{cm}^{2}\right)$ \\
\hline $1.86 \mathrm{eV}$ In GaP & 22.1 \\
\hline $1.42 \mathrm{eV} \mathrm{GaAs}$ & 15.6 \\
\hline $0.66 \mathrm{eV} \mathrm{Ge}$ & 42.4 \\
\hline
\end{tabular}

Table 1 suggests that there is opportunity for significant efficiency gains by exploiting this extreme current mismatch situation. Two such opportunities will be presented in this paper.

Both approaches for higher efficiency as presented here require the growth of epitaxial Ge layers. With MOCVD as the presently preferred growth method, this presents potential difficulties due to the contamination and memory effects associated with growing a group IV material and group $\mathrm{II}-\mathrm{V}$ materials in the same reactor. The scope of this paper is not to suggest that this problem can and should be overcome, but rather to present the results of a modeling study that establishes what efficiency gains are possible and what the design requirements are. This information can then be used to more effectively evaluate the feasibility of either of these approaches in production.

\section{DEVICE STRUCTURES}

Approach 1 is shown schematically in Figure $1 \mathrm{~b}$ and involves adding a second $G e$ subcell to the InGaP/GaAs/Ge multi-junction such that absorption of the near infrared spectrum is divided between two $\mathrm{Ge}$ subcells rather than one. The resulting four junction In GaP/GaAs/Ge/Ge device benefits from an increased open circuit voltage as contributed by the second $\mathrm{Ge}$ subcell.

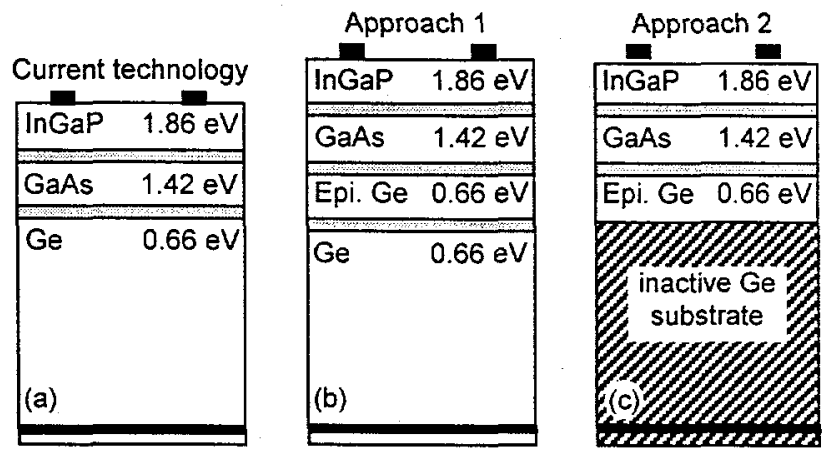

Fig. 1. A comparison of the device structures of current triple junction technology (a) and the improved efficiency approaches presented in this paper ( $b$ and $c$ ).

The ideal bandgap combination for a four junction series interconnected solar cell is approximately 2.0/1.4/1.0/0.7 eV. Although insertion of a second $\mathrm{Ge}$ subcell into the triple junction device structure is far from the ideal bandgap combination for a four junction device, there is presently a lack of other lattice matched materials with suitable bandgaps between that of GaAs and $\mathrm{Ge}$ to fill this role. The development of new $\sim 1 \mathrm{eV}$ materials as currently pursued by several groups [1-3] is attractive because the resulting bandgap combination would be very close to ideal. However, $\sim 1 \mathrm{eV}$ materials with sufficient photovoltaic quality have not yet been demonstrated. 


\section{DISCLAIMER}

This report was prepared as an account of work sponsored by an agency of the United States Government. Neither the United States Government nor any agency thereof, nor any of their employees, make any warranty, express or implied, or assumes any legal liability or responsibility for the accuracy, completeness, or usefulness of any information, apparatus, product, or process disclosed, or represents that its use would not infringe privately owned rights. Reference herein to any specific commercial product, process, or service by trade name, trademark, manufacturer, or otherwise does not necessarily constitute or imply its endorsement, recommendation, or favoring by the United States Government or any agency thereof. The views and opinions of authors expressed herein do not necessarily state or reflect those of the United States Government or any agency thereof. 


\section{DISCLAIMER}

Portions of this document may be illegible in electronic image products. Images are produced from the best available original document. 
Approaches 1 and 2 as presented here are alternative paths towards higher efficiency that leverage the well understood material properties, very high hole and moderately high electron intrinsic mobilities, and relatively well established MOCVD growth methods $[4,5]$ offered by epitaxial germanium technology.

Approach 2 is shown schematically in Figure 1c and improves the performance of current triple junction technology by thinning the active layer of the $\mathrm{Ge}$ subcell. The Ge subcell in present InGaP/GaAs/Ge triple junctions is uniquely suited to exploiting the well-known trade-off between Voc and Jsc that occurs with a decrease in the subcell thickness. The result is a triple junction with improved open circuit voltage resulting from the improved Ge subcell Voc.

\section{MODELING RESULTS}

\section{Approach 1}

Both Ge subcells in the four junction device shown in Figure $1 \mathrm{~b}$ must be capable of generating enough short circuit current so as not to current limit the device. A simple analytical model has been used to plot the maximum photocurrent achievable in a single Ge layer as a function of the layer thickness. The results are shown in Figure 2. A $3.0 \mu \mathrm{m} \mathrm{GaAs}$ filter is included in the model to optically simulate inclusion in a triple junction. Perfect collection efficiency and zero front and back surface reflectivity have been assumed.

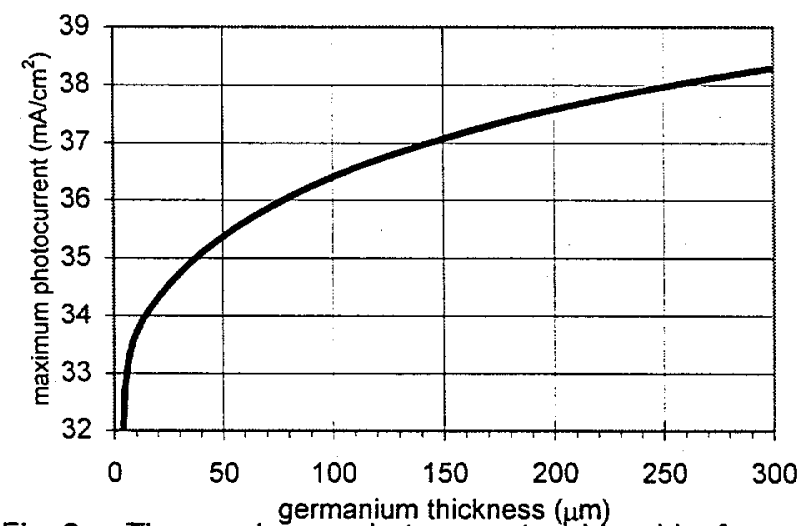

Fig. 2. The maximum photocurrent achievable from a GaAs filtered $\mathrm{Ge}$ subcell as a function of the subcell thickness.

Figure 2 suggests that approximately $37 \mathrm{~mA} / \mathrm{cm}^{2}$ of photocurrent is available to the Ge subcell for a typically used substrate thickness of $140 \mu \mathrm{m}$. This implies that dividing this current between two Ge subcells can result in as much as $18.5 \mathrm{~mA} / \mathrm{cm}^{2}$ of photocurrent and is sufficient so as not to current limit the multi-junction, assuming a target device $\mathrm{Jsc}$ of $17 \mathrm{~mA} / \mathrm{cm}^{2}$.

Assumptions made in the model elucidate several design and performance requirements. First, the collection efficiency for both $\mathrm{Ge}$ subcells must be reasonably close to unity. This requires adequate surface passivation, sufficient minority carrier diffusion lengths, and good control of layer interdiffusion and auto-doping such that sufficient emitter and junction quality is maintained. As reported elsewhere, the $\mathrm{Ge}$ subcell collection efficiency in current triple junctions is limited by emitter recombination due to poor control of interdiffusion during the growth process [6]. It is also unclear whether the $\mathrm{Ge}$ subcell emitter surface is well passivated at present. Second, device reflectance must be better controlled for wavelengths out to approximately $1.8 \mu \mathrm{m}$.

Addressing these performance losses has not been of paramount importance for current triple junction technology due to the excess current generating capability of the Ge subcell. However, these issues must be resolved for approach 1 to be feasible. These design requirements are not unique to approach1; they must also be addressed for the 2.0/1.4/1.0/0.7 eV four junction approach, or any technology that requires near unity quantum efficiency from a Ge subcell.

Additional, more refined modeling has been conducted to determine the epitaxial Ge (subcell 3) thickness that would be required to divide the photocurrent equally between the epitaxial $\mathrm{Ge}$ and the substrate $\mathrm{Ge}$ subcells. The results of that modeling are shown in Figure 3.

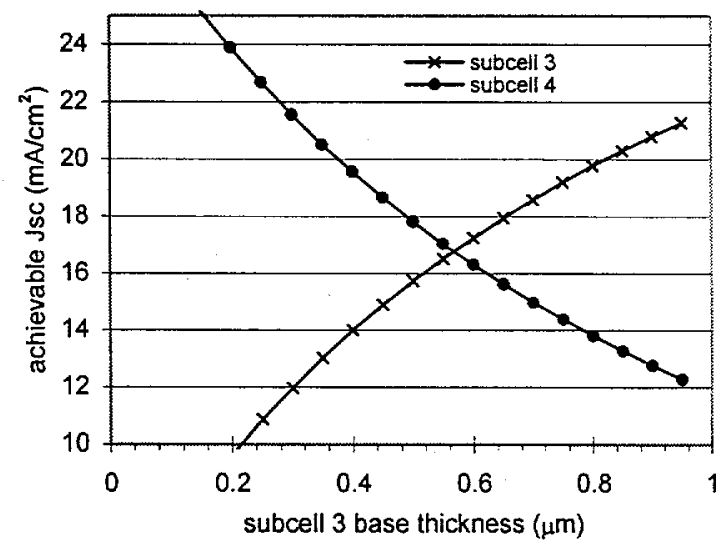

Fig. 3. Achievable Jsc for both Ge subcells as a function of the epitaxial $\mathrm{Ge}$ (subcell 3) base thickness.

Figure 3 was generated using analytical modeling to calculate the achievable Jsc of each of the Ge subcells as a function of the thickness of the epitaxial Ge subcell base region thickness. An $n / p$ configuration and $3.0 \mu \mathrm{m}$ GaAs filter were assumed. High efficiency emitters with thicknesses of $0.1 \mu \mathrm{m}$ were assumed for both subcells. Auger recombination coefficients from Karpova et al. were used to model recombination in the emitter [7]. Mobility models were adapted from Prince [8] and Tyler et al. [9]. Moderate surface recombination velocities of $5 \times 10^{3} \mathrm{~cm} / \mathrm{s}$ were used for all surfaces except the back surface of subcell 4 , where a recombination velocity of $1 \times 10^{7} \mathrm{~cm} / \mathrm{s}$ was used to simulate the poor surface passivation expected at a planar ohmic back contact. A uniform front reflectance of $5 \%$ was assumed. Minority carrier lifetimes of $5 \mu$ s were used for the base region of both $\mathrm{Ge}$ subcells. Parameter fitting (using PC1D [10]) of experimentally measured internal quantum efficiency data from triple junction cells was used to determine the appropriate minority carrier lifetime for use in this modeling. The triple junction cells used in the parameter fit were irradiated with

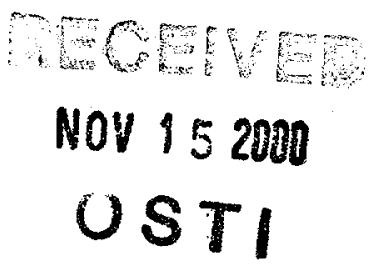


$1 \times 10^{15} \mathrm{~cm}^{-2}$ of $1 \mathrm{MeV}$ electrons. This lifetime represents a reasonable lower limit for epitaxial Ge material at end-oflife. Hole lifetimes of $0.45 \mu \mathrm{s}$ have been reported for $n$ type $-1 \times 10^{18} \mathrm{~cm}^{-3}$ doped Ge grown on GaAs [5]. Lifetime models from Karpova et al. [7] suggest that this lifetime is Auger limited, and therefore that lifetimes near $5 \mu \mathrm{s}$ are plausible at lower doping levels.

Figure 3 suggests that an approximately $0.6 \mu \mathrm{m}$ thick epitaxial $\mathrm{Ge}$ subcell is optimum for dividing the available photocurrent equally between both $\mathrm{Ge}$ subcells. Figure 3 also suggests that achieving $16.8 \mathrm{~mA} / \mathrm{cm}^{2}$ from both $\mathrm{Ge}$ subcells is achievable with reasonably good material quality and surface passivation.

The theoretical efficiency of approach 1 is compared to that of current triple junction technology in Table 2. Theoretical data was generated using modeling approaches similar to that of Fan et al. [11] and Nell et al. [12], and using a dark current model given by Green [13]. A theoretical efficiency of over $30 \%$ is predicted for approach 1.

Table 2. A comparison of practical and theoretical performance for approach 1 versus current triple junction technology (AMO).

\begin{tabular}{|c|c|c|c|c|}
\cline { 2 - 4 } \multicolumn{1}{c|}{} & $\begin{array}{c}\text { Current } \\
\text { 3-junction }\end{array}$ & $\begin{array}{c}\text { Approach 1: } \\
\text { 4-junction }\end{array}$ & change \\
\hline \multicolumn{2}{|c|}{ Theoretical Eff (\%) } & 28.7 & 30.8 & 2.1 \\
\hline \multirow{2}{*}{$\mathrm{g}$} & Efficiency (\%) & 26.5 & 28.0 & 1.5 \\
\hline \multirow{2}{*}{$\mathrm{g}$} & $\operatorname{Voc}(\mathrm{V})$ & 2.59 & 2.80 & 0.21 \\
\cline { 2 - 5 } & $\mathrm{Jsc}\left(\mathrm{mA} / \mathrm{cm}^{2}\right)$ & 16.8 & 16.8 & 0 \\
\cline { 2 - 5 } & $\mathrm{FF}$ & 0.83 & 0.81 & -0.02 \\
\hline
\end{tabular}

A practical comparison of approach 1 versus current triple junction technology is also shown in Table 2 and is identified as "modeled" data. Analytical models were used to generate current-voltage characteristics for each subcell. The resulting multi-junction electrical output parameters were then determined numerically. The $\mathrm{Ge}$ subcell model used to generate Figure 3 was also used here, along with triple junction current-voltage characteristics typical of production devices. Results suggest that a 1.5 absolute percent efficiency gain can be expected, resulting from a $210 \mathrm{mV}$ addition to the Voc.

The expected efficiency gain offered by approach 1 depends primarily on the Voc contributed by the additional $\mathrm{Ge}$ subcell. The $210 \mathrm{mV}$ gain assumed in the previous analysis is typical of current $\mathrm{Ge}$ subcell technology. However, this does not preclude significant future advances in Ge subcell Voc resulting from further subcell design improvements. Figure 4 shows the expected absolute efficiency gain that can be expected with approach 1 as a function of the epitaxial Ge subcell Voc.

\section{Approach 2}

A fundamental trade-off in solar cell design is the cell thickness. In cases where back surface passivation is adequate, decreasing the cell thickness results in an increased open circuit voltage at the expense of a decreased short circuit current density. The triple junction InGaP/GaAs/Ge solar cell shown in Figure 1c represents a solar cell uniquely suited to overcome the fundamental Jsc versus Voc trade-off that is inherent in solar cell design. Decreasing the thickness of the Ge subcell has essentially no effect on the short circuit current of the multi-junction due to the large amount of excess photocurrent generated by the Ge subcell. Decreasing the thickness of the Ge subcell can therefore result in an increased subcell and multi-junction Voc without a tradeoff in device Jsc. Modeling presented in Figure 3 suggests that the Ge subcell can be as thin as 1 micron and not limit the current of the InGaP/GaAs/Ge triple junction, assuming a target device $\mathrm{Jsc}$ of $17 \mathrm{~mA} / \mathrm{cm}^{2}$.

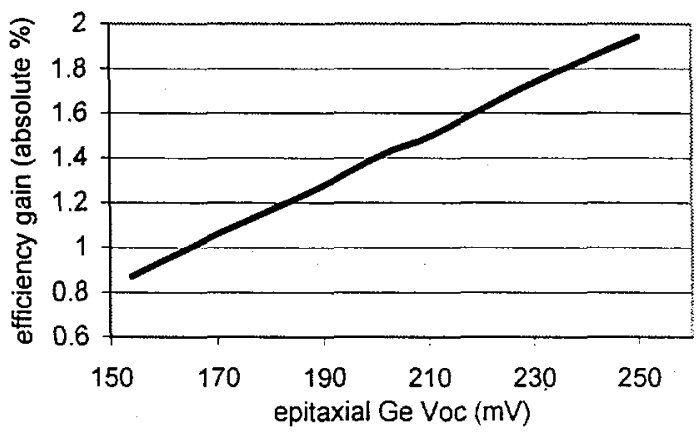

Fig. 4 The efficiency gain expected from approach 1 as a function of the epitaxial Ge subcell Voc.

The voltage gain that can be expected via a decrease in the base region thickness is very sensitive to both the minority carrier lifetime and back surface recombination velocity. Additionally, subcell recombination must be base region limited. PC1D has been used to model the expected gain in the Ge subcell Voc as a function of the base region thickness. The results are shown in Figure 5 .

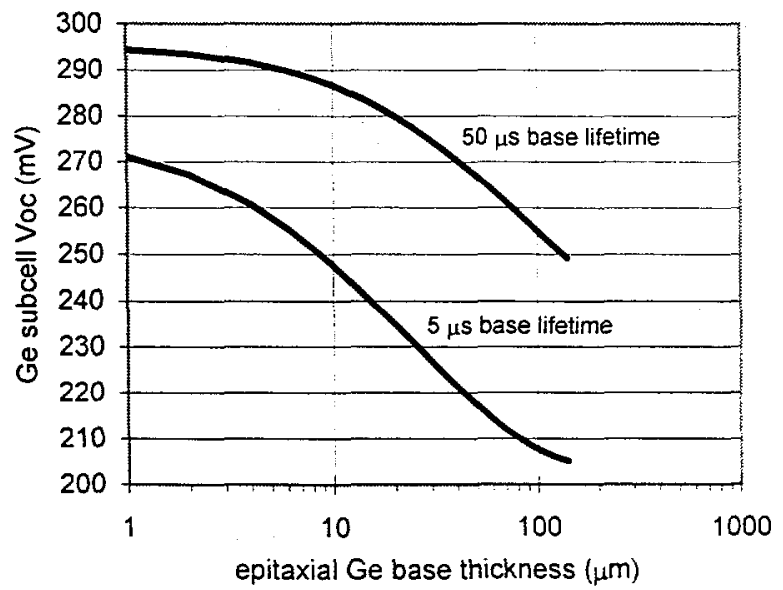

Fig. 5. Ge subcell Voc as a function of the base region thickness. 
The n-type emitter region thickness and carrier concentration used were $0.1 \mu \mathrm{m}$ and $1 \times 10^{18} \mathrm{~cm}^{-3}$, respectively. Front surface recombination velocity was assumed zero. These parameters assure that device recombination is base region limited. Substrate thickness and carrier concentration were $140 \mu \mathrm{m}$ and $1 \times 10^{18} \mathrm{~cm}^{-3}$, respectively. A back surface recombination velocity of $1 \times 10^{7} \mathrm{~cm} / \mathrm{s}$ was assumed to appropriately model a planar onmic back contact. Effective surface passivation is achieved via the high-low junction formed between the substrate and epitaxial material. The carrier concentration of the latter was $5 \times 10^{16} \mathrm{~cm}^{-3}$. A substrate carrier concentration of $1 \times 10^{18} \mathrm{~cm}^{-3}$ resulted in the most effective back surface field and therefore the greatest Voc gain with reduced thickness. A bandgap narrowing model approximating that of Jain et al. was used for the p-type $\mathrm{Ge}$ [14]. Two different base lifetimes were modeled to cover the likely range of values for this parameter. A $5 \mu \mathrm{s}$ electron lifetime represents a likely lower limit at end-oflife as discussed previously.

The modeling data from Figure 5 was then used to determine the efficiency gain expected from approach 2. The results of that comparison are shown in Table 3.

Table 3. A comparison of modeled efficiencies for approach 2 versus current triple junction technology (AMO).

\begin{tabular}{|c|c|c|c|}
\cline { 2 - 4 } \multicolumn{1}{c|}{} & $\begin{array}{c}\text { Current } \\
\text { 3-junction }\end{array}$ & $\begin{array}{c}\text { Approach 2: } \\
\text { triple junction } \\
\text { with thin Ge }\end{array}$ & change \\
\hline Efficiency (\%) & 26.5 & 27.8 & 1.3 \\
\hline $\mathrm{Voc}(\mathrm{V})$ & 2.590 & 2.650 & 0.060 \\
\hline $\mathrm{Jsc}\left(\mathrm{mA} / \mathrm{cm}^{2}\right)$ & 16.8 & 16.8 & 0 \\
\hline $\mathrm{FF}$ & 0.83 & 0.85 & 0.02 \\
\hline
\end{tabular}

The efficiency gain expected from approach 1 is greater than that expected from approach 2 , particularly if a large Voc can be achieved from the epitaxial Ge subcell. However, approach 1 is structurally more complex and may require heteroepitaxial growth of $\mathrm{Ge}$ on higher bandgap layers, as is typically done to implement tunnel junction interconnects, window layers, or back surface field layers. Furthermore, approach 1 is comparatively more sensitive to absorption or collection losses within the $\mathrm{Ge}$ subcell. This results from the requirement to divide the near-IR spectrum between two $\mathrm{Ge}$ subcells. Approach 1 therefore assumes a larger technical risk than approach 2.

\section{CONCLUSION}

Two approaches for improving the performance of group III-V multi-junction solar cells have been presented. These approaches use epitaxial germanium structures to capitalize on the extreme current mismatch and excess current generating capability of the germanium subcell in present InGaP/GaAs/Ge solar cells. The theoretical AMO efficiency is over $30 \%$. Modeling results have been presented which suggest that an efficiency gain of at least $1.5 \%$ absolute is possible.

\section{REFERENCES}

[1] S.R. Kurtz, A.A. Allerman, E.D. Jones, J.M. Gee, J.J. Banas, Appl. Phys. Lett. 74, 1999, pp. 729-731.

[2] D.J. Friedman, J.F. Geisz, S.R. Kurtz, J.M. Olson, J. Crystal Growth 195, 1998, pp. 409-415.

[3] J.F. Geisz, D.J. Friedman, J.M. Olson, S.R. Kurtz, R.C. Reedy, A.B. Swartzlander, B.M. Keyes, A.G. Norman, Appl. Phys. Lett. 76, 2000, pp. 1443-1446.

[4] J.E. Ayers, S.K. Ghandhi, J. Crystal Growth 89, 1988, pp. 371-377.

[5] R. Venkatasubramanian, M.L Timmons, S. Bothra, J.M. Borrego, J. Crystal Growth 112, 1991, pp. 7-13.

[6] N.H. Karam, R.R. King, B.T. Cavicchi, D.D. Krut, J.H. Ermer, M. Haddad, L. Cai, D.E. Joslin, M. Takahashi, J.W. Eldredge, W.T. Nishikawa, D.R. Lillington, B.M. Keyes, R.K. Ahrenkiel, IEEE Trans. Elect. Dev. 46, 1999, pp. 2116-2125.

[7] I.V. Karpova, S.G. Kalashnikov, Int. Conf. on the Phys. of Semiconductors., 1962, pp. 880-885.

[8] M.B. Prince, Phys. Rev. 92, 1953, pp. 681-687.

[9] W.W. Tyler, H.H. Woodbury, Phys. Rev. 102, 1956, pp. 647-655.

[10] P.A. Basore, D.A. Clugston, $25^{\text {th }}$ IEEE PVSC, 1996, pp. 377-380.

[11] J.C.C. Fan, B-Y. Tsaur, B.J. Palm, $16^{\text {th }}$ IEEE PVSC, 1982 , pp. $692-701$.

[12] M.E. Nell, A.M. Barnett, IEEE Trans. Elect. Dev. ED-34, 1987, pp. 257-265.

[13] M.A. Green, Solar Cells, Prentice-Hall, Englewood Cliffs, N.J., p. 88.

[14] S.C. Jain, D.J. Roulston, Sol. St. Elect. 34, 1991, pp. 453-465.

\section{ACKNOWLEDGMENT}

Sandia National Laboratories is a multiprogram laboratory operated by Sandia Corporation, a Lockheed Martin Company, for the United States Department of Energy under Contract DE-AC04-94AL85000. 